\title{
Erratum: Buffeting performance of long-span suspension bridge based on measured wind data in a mountainous region
}

\section{Yang Yang ${ }^{1}$, Yao Gang ${ }^{2}$, Fujia Wei ${ }^{3}$, Weihe Qin ${ }^{4}$}

Key Laboratory of New Technology for Construction of Cities in Mountain Area, Ministry of Education, Chongqing, China

School of Civil Engineering, Chongqing University, Chongqing, China

${ }^{1}$ Corresponding author

E-mail:19y20052710@163.com, ${ }^{2}$ yaocqu@vip.sina.com, ${ }^{3} 20151601020 @ c q u . e d u . c n$, 420151602015t@cqu.edu.cn

DOI https://doi.org/10.21595/jve.2019.20861

Check for updates

Copyright $(C 2019$ Yang Yang, et al. This is an open access article distributed under the Creative Commons Attribution License, which permits unrestricted use, distribution, and reproduction in any medium, provided the original work is properly cited.

\section{Publisher's note regarding paper}

Yang Yang, Gang Yao, Wei Fujia, Qin Weihe Buffeting performance of long-span suspension bridge based on measured wind data in a mountainous region. Journal of Vibroengineering, Vol. 20, Issue 1, 2018, p. 621-635, https://doi.org/10.21595/jve.2017.18737.

\section{The description of the correction}

The corresponding author number was set incorrectly in the paper finally approved (after the acceptance) by the authors.

Incorrect corresponding author number:

${ }^{2}$ Corresponding author

Revised corresponding author number:

${ }^{1}$ Corresponding author 